\title{
Notas sobre o problema do realismo científico
}

\author{
Remarks on the scientific realism problem
}

Tiago Oliveira ${ }^{1}$

\author{
1 Professor do Departamento de Filosofia do Colégio Pedro II. Faz estágio pós-doutoral na Universidade Estadual do Rio de Janeiro (UERJ) \\ E-mail: iagoluis@ymail.com Orcid: http://orcid.org/0000-0001-7793-9890
}

RESUMO: O problema envolvendo o estatuto ontológico das entidades inobserváveis postuladas pelas teorias científicas é um dos mais centrais em filosofia da ciência. O objetivo deste pequeno artigo é o de oferecer um mapa dos posicionamentos mais recentes, sem a ambição de aprofundá-los. O enfoque será nos principais argumentos a favor e contra a capacidade de a ciência descrever corretamente a realidade natural inobservável (nos mesmos moldes em que é eficaz na descrição dos objetos e processos observáveis). Mais especificamente, exporei o argumento do sucesso para o realismo e uma variação do mesmo, bem como as críticas ao referido argumento, tais como a metaindução pessimista, a subdeterminação das teorias pela evidência (mencionando também uma variação historicista da mesma) e uma abordagem darwinista (do empirismo construtivo), que evita a ideia de sucesso. Concluirei apresentando como tais argumentos exigiram uma seletividade na abordagem realista, hoje concentrada em três ramos cujos nomes estão de acordo com os elementos sobre os quais cada filosofia recomenda ser realista: realismo explanacionista, realismo de entidades e realismo estrutural. Por uma questão de enfoque, darei apenas uma descrição resumida de cada ramo de realismo citado.

Palavras-chave: realismo científico, empirismo construtivo, argumento sem-milagre, metaindução pessimista, subdeterminação.

ABSTRACT: The issue involving the ontological status of the unobservable entities postulated by scientific theories is of major importance in philosophy of science. My aim with this brief paper is to offer a map of the recent debate on the related theme, without the pretension of being profound or exhaustive. My emphasis will be on the main arguments in favor and against the capacity of science in describing correctly the unobservable natural reality (in the same way it is efficacious in describing observable objects and process). More specifically, I will expose the success argument (and one of its variation) and also criticisms of that argument which are: the pessimistic meta-induction, the underdetermination of theories by the evidence (briefly talking about a historicist variation of the argument) and a Darwinist approach offered by constructive empiricism, which denies the success idea. I will conclude this paper showing how those anti-realists arguments demand a selective realist approach, which are recently represented by three kinds of scientific realism: explanationist realism, entities realism and structural realism. Each name represents what are the elements about we should be realists. As being exhaustive is not the aim of this paper, I will only give a summary description of each realism cited above.

Keywords: scientific realism, constructive empiricism, no-miracle argument, pessimistic meta-induction, undetermination

\section{Introdução}

O realismo, em linhas gerais, é a postura filosófica (mais especificamente metafísica) que admite a 
existência de uma realidade para além de nossas mentes e que, embora nosso conhecimento dessa realidade independente possa variar desde a mais profunda dúvida cética até a mais firme convicção, nossas crenças sobre o mundo não tornam a realidade diferente do que é. Dessa forma, de acordo com o realismo metafísico, nossas crenças são verdadeiras ou falsas porque há uma realidade externa que atesta a correção ou incorreção de tais crenças. Assim Carman define o realismo metafísico:

Tese do realismo metafísico empírico ou do observável ou, simplesmente, realismo do observável: os elementos de $\mathrm{M}$ pertencem a um mundo independente do sujeito cognoscente. É realismo metafísico empírico, ou do observável, porque predica um realismo metafísico do mundo empírico (já que M está definido, fundamentalmente, pelas entidades observáveis), tomando "empírico" em seu sentido mais etimológico, relacionado com a experiência (observável, agregamos) e não só como base de contraste. Note-se que é realismo metafísico empírico e não metafísico somente porque o que se está discutindo não é se existe um mundo externo ao cognoscente, mas se $\mathrm{M}$ o é, o qual quer dizer, se os objetos observáveis (e talvez outros) são externos ao cognoscente. (CARMAN, 2005, p. 46. Grifos do autor)

O problema do realismo científico é um pouco diferente da questão colocada pelo realismo metafísico. Dificilmente cientistas e filósofos da ciência disputam se a realidade observável é independente de nosso conhecimento teórico. Uma vez que teorias têm sido frequentemente substituídas na história da ciência por estar em algum desacordo com os resultados empíricos esperados, isto é, uma vez que experimentos são rigorosamente conduzidos de modo a corroborar ou falsificar teorias científicas, não é muito provável que pesquisadores tanto teóricos quanto experimentais duvidem seriamente de uma instância objetiva (o mundo, a natureza, a realidade ou o que quisermos chamar) em relação à qual poderíamos tratar nossas teorias como mais ou menos próximas da verdade no sentido tarskiano.

A grande disputa nesse sentido é sobre o caráter ontológico que acompanha toda teorização, por mais econômica que esta seja ao introduzir termos que no nosso tratamento ordinário supostamente refeririam a entidades inobserváveis. Quando uma teoria bem-sucedida lança mão de 'elétrons', 'fótons', 'antipartículas' e outros termos cuja existência não pode ser intuída de uma observação simples, ou mesmo de uma observação no microscópio, deveríamos crer que essas entidades são partes constituintes da realidade ou deveríamos simplesmente considerá-las metodologicamente úteis sem nos comprometermos com sua existência? Basicamente, é esse o problema que sustenta a divisão de filósofos da ciência entre realistas e antirrealistas. Reparemos que o problema filosófico não é saber como os cientistas se posicionam, ou como eles agem de fato. O que esperamos saber é se há razões para crer que os termos teóricos são referenciais ou não.

Diversas caracterizações do realismo científico foram propostas e, muitas vezes, elas não fazem justiça a todas as posturas filosóficas autointituladas como realistas. Há, na verdade, uma grande diversidade de tipos de realismo e de antirrealismo científico. Para termos ideia de quantas variações de realismo são possíveis, vale a pena recorrer ao interessante artigo de Carman (2005). No trabalho referido, o autor faz um estudo clarificando o que seria o núcleo do realismo científico, a saber:

(...) a predicação de uma propriedade semântica (verdade, verdade aproximada ou referência), a um objeto científico (lei ou termo teórico) e quantificado (todos, alguns ou a maioria). Na quantificação, por sua vez se clarifica se é determinada ou indeterminada. (CARMAN, 2005, p. 52)

Depois de estabelecido o núcleo do realismo científico, por meio de análise combinatória dentre as várias possibilidades permitidas por esse núcleo, descobre-se que a priori existem pelo menos 1110 tipos de 
posturas relativas ao realismo científico. O autor acrescenta mais um tipo, por precaução, num passo análogo ao feito pelos gregos quando homenagearam o "deus desconhecido", temendo deixar algum deus vingativo de fora de seu panteão. ${ }^{1}$ Trata-se, é claro, não de uma catalogação de todas as posições realistas já defendidas, mas de uma tentativa de contabilizar quantos realismos são possíveis (ainda que alguns deles nunca tenham sido realmente propostos ou venham a ser, dada sua improbabilidade). Embora o ponto realçado possa ser uma razão para não sobrevalorizar a enorme diversidade de realismos, consideramos importante ressaltar tal variação. Segundo Carman, o que seria objeto de debate filosófico mais intenso é a tese que diz respeito ao teórico ou inobservável:

Tese do realismo das entidades teóricas ou, simplesmente, realismo do teórico: ao menos algumas das entidades teóricas são reais no mesmo sentido que as observáveis, ou seja, são reaism. (CARMAN, 2005, p. 47. Grifos do autor $)^{2}$

Chakravartty (2007) apresenta o realismo científico como um compromisso que se desdobra em apenas três dimensões: metafísica, semântica e epistêmica. Metafisicamente o realismo científico estaria comprometido com a existência de um mundo extramental independente. Semanticamente o realismo científico parte do pressuposto de que as leis, propriedades, entidades teóricas, processos e relações propostas pelas teorias científicas devem ser expressas em enunciados que literalmente possuem valor de verdade. Epistemologicamente o realismo entende que as asserções científicas constituem descrições mais ou menos acuradas da natureza. Ou seja, tais asserções são conhecimento, ainda que em variáveis graus de certeza.

Chakravartty sugere que as duas principais fontes de imprecisão que dividem diversos realistas entre si consistem nas ideias de que o realismo se aplica às "nossas melhores teorias" e que tais teorias contêm "verdade aproximada". A primeira é uma razoável atitude de reconhecer que nem todas as teorias propostas ao longo da história seriam verdadeiras e que as únicas candidatas sérias à verdade seriam as teorias mais maduras, isto é, aquelas cujo sucesso explicativo e preditivo é inconteste. Para contornar ainda a vagueza da ideia de 'melhor teoria' ou de 'teoria madura', alguns realistas acrescentam que tais expressões se referem às teorias que permitem novas previsões bem-sucedidas. Na visão desses realistas, só uma teoria capaz de fazer previsões surpreendentes poderia ostentar o título de maturidade. Já a segunda ideia problemática (a de verdade aproximada) seria uma forma de garantir que mesmo teorias falsas podem con-

10 cálculo consiste em tomar 5 quantificadores (todos, a maioria determinada, a maioria indeterminada, alguns determinados, alguns indeterminados), aplicar a um objeto científico (leis, leis centrais, termos teóricos, termos teóricos centrais) e, por sua vez a um predicado (verdadeiras, aproximadamente verdadeiras, referentes). 20 possibilidades para leis e 10 para termos teóricos $=30$ realismos possíveis até aqui. Como leis e termos teóricos fazem parte de teorias determinadas ou não, há 10 (5 quantificadores para teorias determinadas e 5 para indeterminadas) possibilidades para cada uma das 30 já expostas, isto é, 300 possibilidades. Tais possibilidades do núcleo do realismo podem ser literais ou sincrônicos $(300+300=600)$. Podem ser diacrônicos de conservação $(+300)$, diacrônicos de incremento de objetos $(+60)$ de incremento de teorias $(+30)$ ou de incremento de propriedades. Estes últimos podem ser locais $(+100)$ ou globais $(+20)$. Para entender melhor as formas de realismo nomeadas, sugiro a leitura do artigo constante nas referências deste artigo. Carman tem consciência de que há versões redundantes entre as 1110 apresentadas e a $1111^{a}$ variante é apenas uma brincadeira para dizer que não deixou nada de fora.

2 A notação 'real ${ }_{M}$ ' é usada por Carman para designar um objeto que comporia uma realidade independente da mente num marco de realidade $\mathrm{M}$ (que contém todas as entidades observáveis). A escolha do autor mencionado por aquela notação justifica-se por ele pensar que 'real' é um termo relativo ao marco de realidade escolhido. No discurso ficcional, para citar um exemplo diferente, Don Quixote é realc, isto é, pertence ao mundo descrito pela obra de Cervantes, ao passo que Homer Simpson não é realc. No realismo científico, procura-se estabelecer a pertença de algumas entidades teóricas ao mesmo marco de realidade a que pertencem as entidades observáveis. 
ter explicações com alguma precisão. Além do mais, um bom número de realistas admite que diversas mudanças teóricas resultem em progresso, no qual cada mudança nos deixaria mais e mais perto da verdade.

Há pelo menos três grandes famílias de realismo científico, sobre as quais trataremos muito brevemente no fim deste trabalho, a saber: realismo explanacionista, realismo de entidades e realismo estrutural. Embora tracem diferentes argumentos para defender o realismo, as três famílias compartilham de uma mesma estratégia: adotam um esquema seletivo dos elementos sobre os quais devemos ser realistas. Ficará mais clara a razão pela qual os posicionamentos mais recentes no debate prezam pela seletividade quando se vislumbra as críticas às quais o realismo científico está sujeito. A seguir, tentarei expor os argumentos mais recorrentes no debate em questão.

\section{0 argumento do sucesso ou argumento sem-milagre}

Um argumento bastante recorrente para a defesa do realismo científico veio de Hilary Putnam, ainda em sua fase realista. Segundo ele, o realismo científico "é a única filosofia que não faz do sucesso da ciência um milagre” (PUTNAM, 1975, p. 73). Dentre as explicações possíveis para o sucesso da ciência, a mais promissora parece ser a de que as teorias são (aproximadamente) verdadeiras. O argumento, também chamado de argumento sem milagre e de argumento do sucesso, é uma forma de inferência para a melhor explicação, também conhecida pelo nome de abdução ou hipótese. Tal inferência é um argumento não dedutivo que Peirce (1839-1914) sugeriu estar por trás do método científico, especificamente no que trata de escolha dentre explicações alternativas. Quando um fato F é surpreendente, mas não o seria caso uma hipótese H fosse verdadeira, estaríamos justificados em crer que $\mathrm{H}$ é provável e aproximadamente verdadeira por ser a melhor explicação para F. Formalmente, a inferência pela melhor explicação poderia ser expressa assim:

$$
\begin{aligned}
& \mathrm{A} \rightarrow\left(\mathrm{B}_{1} \Lambda \mathrm{B}_{2} \Lambda \ldots \Lambda \mathrm{B}_{\mathrm{n}}\right) \\
& \mathrm{B}_{1} \Lambda \mathrm{B}_{2} \Lambda \ldots \Lambda \mathrm{B}_{\mathrm{n}-1}
\end{aligned}
$$

$\therefore \mathrm{A}$

Para esse modo de raciocinar, a ocorrência de uma série de eventos $\left(B_{1} \ldots B_{n-1}\right)$ que seriam implicados pelo evento A conta a favor de A como melhor explicação dessa série. Dentre as várias explicações para o carro $\left(B_{1}\right)$, o jardim $\left(B_{2}\right)$ e o telhado $\left(B_{3}\right)$ estarem molhados, a melhor parece a chuva (A), muito embora não haja garantias de que cada evento não tenha causas distintas. No caso do argumento definitivo para o realismo, a formulação parece ser a seguinte, onde o termo 'sucesso' implica previsões acuradas, explicações unificadas de fenômenos dispersos, aparato tecnológico etc.:

Premissa 1: O sucesso da ciência é surpreendente;

Premissa 2: Tal sucesso não seria surpreendente se as melhores teorias correntes fossem (aproximadamente) verdadeiras;

Conclusão: Portanto é provável que as nossas melhores teorias correntes sejam (aproximadamente) verdadeiras.

Para os defensores do argumento sem milagre, a verdade das teorias explicaria muito bem a proximidade entre os resultados previstos e os medidos, a eficácia dos instrumentos produzidos em conformidade com tais teorias e as retrodições (explicações de fatos já conhecidos, incluindo o sucesso passado das teorias superadas). Caso as melhores teorias não fossem ao menos aproximadamente verdadeiras, tal sucesso seria um fato surpreendente.

Segundo Putnam, o realismo não seria apenas uma hipótese metafísica, mas uma teoria científica, 
isto é, uma maneira testável de explicar o fenômeno empírico do sucesso das teorias científicas maduras. De acordo com o filósofo, há fatos envolvendo a história da ciência que permitem sustentar o realismo como uma hipótese científica empiricamente suportada. Um exemplo disso é a constatação de que várias das teorias antigas eram apenas casos limites das teorias maduras atuais. Conforme diz Putnam,

[...] realismo é uma teoria empírica. Um dos fatos que essa teoria explica é o fato de que as teorias científicas tendem a 'convergir' no sentido de que teorias mais antigas são, muito frequentemente, casos limites das mais recentes (este é o motivo pelo qual é possível considerar que os termos teóricos preservam sua referência durante a maioria das mudanças de teoria). (PUTNAM, 1978, p.123)

Não há dúvidas de que a inferência para a melhor explicação é um procedimento recorrente nas ciências naturais e sociais. A teoria evolutiva de Darwin, por exemplo, mostra-se um caso exemplar desse padrão inferencial, pois constitui uma explicação coerente com a diversidade das espécies animais, suas características adaptativas, a existência de fósseis que não correspondem a esqueletos de animais atualmente existentes etc. Adicionalmente, a teoria evolutiva não pressupõe um criador exmachina ou um projetista inteligente controlando a natureza e sustentando o equilíbrio natural, tornando-se uma explicação mais simples do que suas rivais.

O argumento sem milagre é bastante utilizado para sustentar a plausibilidade do realismo científico porque além de explicar o sucesso preditivo, explicativo e prático da ciência, também sugere uma convergência para a verdade nas sucessões de teorias num mesmo domínio de conhecimento.

\section{Uma crítica historicista ao argumento do sucesso: a metaindução pessimista}

Contra o argumento do sucesso, pode-se levantar o fato de que a história da ciência é um cemitério de teorias e de entidades teóricas. A metaindução pessimista é um desafio baseado na história da ciência que contesta a correlação entre sucesso e verdade, tal como proposta pelo argumento sem milagre de Putnam. O prefixo meta- é utilizado por tratar-se de um argumento sobre teorias. E é, aliás, controverso que seja mesmo uma indução, mas este é um debate para outro momento. ${ }^{3}$ Mais recentemente, foi Larry Laudan, num artigo intitulado $A$ confutationofconvergentrealism(1981), quem formulou uma crítica bastante repercutida ao argumento sem-milagre baseando em casos retirados da história. A estratégia de Laudan no artigo citado é mostrar que a relação entre sucesso, referência e verdade não se dá naturalmente como querem os realistas. Para o propósito da argumentação que demonstra que sucesso empírico não é nem condição suficiente, nem necessária para uma teoria ser referencial, Laudan mencionou casos históricos em que reconhecemos (a) teorias com termos referenciais embora empiricamente fracassadas e (b) teorias com termos não referenciais embora bem-sucedidas.

Exemplos que corroboram (a) seriam as várias teorias atômicas que precederam as atuais. O termo 'átomo' é considerado referencial de acordo com a interpretação realista de nosso conhecimento atual, embora os modelos atômicos obsoletos tenham falhado em realizar previsões bem-sucedidas e explicações aceitáveis. Na verdade, como ressalta Laudan, é extremamente fácil criar teorias genuinamente referenciais e massivamente falsas. Se se pode fazer isso com hipóteses envolvendo entidades observáveis (ex: o mode-

3 Discuto sobre como melhor formular a metaindução pessimista em Oliveira (2014). Há filósofos como Psillos (1999) que consideram a mesma uma reductioe outros como Lyons (2002) que a consideram um modus tollens pessimista. 
lo geocêntrico de Ptolomeu), muito mais é possível em relação a termos teóricos cuja referência, a princípio, não pode ser verificada a olho nu. Talvez algum realista convergente dissesse que a substituição das teorias antigas por hipóteses melhores foi um passo em direção a uma teoria mais próxima da verdade, o que é atestado pela preservação dos termos referenciais e pela melhor adequação empírica da nova teoria. Mas a simples existência de uma teoria genuinamente referencial, embora hoje indiscutivelmente falsa, levanta dúvidas se o sucesso empírico é condição necessária para uma teoria genuinamente referencial.

O caso é que também teorias bem-sucedidas são também substituídas e, ao contrário do que foi discutido nos exemplos anteriores, os termos teóricos das teorias abandonadas passam a ser considerados não referentes. Uma lista de exemplos favorece (b):

1. as esferas cristalinas da astronomia antiga e medieval;

2. a teoria dos humores da medicina;

3. a teoria dos eflúvios da eletricidade estática;

4. a geologia catastrofista com seu comprometimento com o dilúvio universal (de Noé);

5. a teoria do flogisto da química;

6. a teoria do calórico;

7. as teorias da força vital da fisiologia;

8. o éter eletromagnético;

9. o éter óptico;

10. a teoria da inércia circular;

11. teorias da geração espontânea. (LAUDAN, 1981, p. 33)

Para ficarmos somente em um caso, consideremos o sucesso explicativo que as teorias do éter tiveram antes de serem substituídas por teorias que dispensavam a entidade: o éter óptico explicava a reflexão, a difração, interferência, dupla refração, difração e polarização, além do que permitia fazer algumas previsões. É um perfeito caso de teoria bem-sucedida. O que se segue da história de teorias como as que foram acima mencionadas é que nem teorias referentes são necessariamente bem-sucedidas nem teorias bem-sucedidas (em sua época) são necessariamente referentes (segundo as teorias atuais).

\section{Contestações da inferência para a melhor explicação}

Uma das posturas antirrealistas mais defendidas atualmente é o empirismo construtivo de van Fraassen (1980). No lugar de considerar, tal como os positivistas do início do século XX, que os termos teóricos fossem mera abreviação para uma série de procedimentos empíricos ou, ainda, que enunciados contendo termos teóricos fossem destituídos de valor de verdade, van Fraassen sustentou que teorias contendo referências a entidades inobserváveis seriam verdadeiras ou falsas. Além do mais, o autor não nega que observações sejam, muitas vezes, dependentes de teorias. O problema do empirista construtivo com a tese do realismo científico estaria na dimensão epistêmica ali implicada. No que tange os enunciados contendo entidades inobserváveis a olho nu, podemos apenas supor tratar-se de uma descrição possível, mas não podemos saber que as coisas são tal como afirma a teoria em questão. É como se esbarrássemos numa barreira imposta pela nossa natureza fisiológica. O objetivo da ciência não é, segundo van Fraassen, dar explicações corretas do ponto de vista do inobservável e nem aproximar da verdade, mas tão somente buscar teorias que sejam empiricamente adequadas, isto é, que "salvem os fenômenos". Nesse sentido, sua crítica ao argumento de Putnam é direcionada primeiramente à meta da ciência, mas também à validade e à 
necessidade da inferência para a melhor explicação, uma vez que não é a explicação o objetivo da criação de teorias. Ao minar a inferência à melhor explicação como guia para a verdade, van Fraassen considerará ilegítimo o próprio fundamento do argumento sem milagre.

Além do mais, o autor de The scientificimage sustenta que a ciência pode ser entendida como uma competição na qual as teorias mais adequadas permanecem. Essa visão darwinista da ciência dispensa o argumento do sucesso uma vez que reconhece que, para cada teoria bem-sucedida, há um amontoado de teorias que falharam, de modo que seria falso caracterizar a ciência como um empreendimento de sucesso:

[...] alego que o sucesso das teorias científicas comuns não é nenhum milagre. Não é nem mesmo surpreendente para a mente científica (darwinista). Pois toda teoria científica nasce em uma vida de competição feroz, uma selva de dentes e garras ensanguentadas. Apenas as teorias bem-sucedidas sobrevivem - aquelas que, de fato, agarram as reais regularidades da natureza. (VAN FRAASSEN, 2007, p. 81)

Qualquer que seja o mérito da analogia de van Fraassen entre teorias bem adaptadas e organismos bem adaptados, o certo é que ela ainda não impede que sejam buscadas explicações de por que razões uma teoria sobrevivera e tem sobrevivido. Uma possível alegação é de que só as teorias aproximadamente verdadeiras perduram na competição. Ademais, como afirma Chakravartty, dizer que "teorias bem-sucedidas são as bem adaptadas pode ser equivalente à tautologia de que teorias bem sucedidas são bem sucedidas, o que não é dizer muito" (2007, p.5).

Não é difícil perceber, entretanto, quão sedutora pode ser a proposta do empirismo construtivo. Afinal, van Frassen apenas exige que teorias salvem os fenômenos, ao passo que isso não é suficiente para o realista, que requer uma descrição (aproximadamente) verdadeira. Por outro lado, acredita-se que uma teoria verdadeira será empiricamente adequada. A diferença aqui está no fato de que o empirismo construtivo oferece uma meta tangível (pelo menos aproximadamente dentro de um horizonte possível), enquanto uma inferência para a melhor explicação esbarra na possibilidade de a melhor explicação não ser a verdadeira.

Chakravartty considera duas ressalvas à inferência pela melhor explicação como meio de descobrir uma teoria verdadeira: $\left(1^{\circ}\right)$ seria primeiramente necessário hierarquizar as teorias rivais quanto à sua proximidade com a verdade (o que seria complicado pela dificuldade em dizer quais características uma teoria provavelmente verdadeira precisa possuir) e, finalmente, $\left(2^{\circ}\right)$ que uma explicação verdadeira estivesse disponível no rol de explicações possíveis.

Não fica nada claro que os critérios sugeridos para a melhor explicação impliquem ao menos probabilisticamente a verdade, muito menos que seja possível garantir que a explicação verdadeira esteja entre as disponíveis. Muitos critérios da primeira condição (de que é possível graduar explicações quanto à proximidade com a verdade) são sugeridos por defensores da inferência à melhor explicação, tais como: simplicidade, elegância e unidade. Mas não se sabe se tais critérios conseguem distinguir teorias aproximadamente verdadeiras quanto à sua relativa proximidade com a verdade. Já sobre a segunda condição, não parece haver qualquer garantia de saber que há uma hipótese verdadeira dentre as oferecidas:

Não há, a priori, razão, alguém poderia argumentar, para rejeitar a possibilidade de que fenômenos naturais sejam [ao contrário da primeira condição] complexos, deselegantes e desunidos. E a respeito da segunda condição, para uma inferência pela melhor explicação bem-sucedida, na maioria dos casos é difícil de ver como alguém poderia saber de antemão que uma hipótese verdadeira está entre as consideradas. (CHAKRAVARTTY, 2007, p. 6) 
$\mathrm{Na}$ dificuldade em demonstrar que os critérios acima tratados impliquem uma prioridade de uma dentre duas ou mais explicações alternativas, o realismo pode acabar sucumbindo frente a outro problema, que exporemos a seguir: a chamada subdeterminação da teoria pela evidência empírica.

Há outra razão pela qual o empirismo construtivo é um posicionamento bastante plausível. Tratase da dificuldade de escolher entre teorias rivais que sejam igualmente adequadas do ponto de vista da observação dos fenômenos. Em alguns casos, pode vir a ser impossível determinar uma teoria vencedora porque se 'T e 'T' são competidoras e concordarem com todas as evidências experimentais disponíveis, um realista teria razões para adotar tanto a ontologia de T quanto a de T'. Essa possibilidade ficou conhecida pela expressão 'subdeterminação da teoria pela evidência empirica' (abreviadamente "subdeterminação").

Sustenta-se que a subdeterminação tenha sido proposta pelo físico e filósofo francês P. Duhem e pelo lógico americano W.O. Quine como consequência do problema que levou o nome de ambos. Originalmente o problema de Duhem-Quine é sobre o fato de que nenhuma hipótese é testada sozinha, mas depende de hipóteses auxiliares. Isso faz com que, caso os resultados de um procedimento estejam em desacordo com o esperado, sempre pode haver dúvida se a hipótese central deve ser abandonada ou se o problema está nas hipóteses de fundo. Essa indeterminação pode comprometer a escolha do grupo de hipóteses que devem ser consideradas corretas, pois há mais de uma possibilidade de escolha. Formalmente teríamos a seguinte situação, onde $\mathrm{H}_{\mathrm{c}}$ é a hipótese central; $\mathrm{H}_{1}, \mathrm{H}_{2}$ e $\mathrm{H}_{3}$ são as hipóteses auxiliares e E é a consequência empírica esperada no teste:

(1) $\left(\mathrm{H}_{\mathrm{c}} \wedge \mathrm{H}_{1} \wedge \mathrm{H}_{2} \wedge \mathrm{H}_{3}\right) \rightarrow \mathrm{E}$

(2) $\neg \mathrm{E}$

(3) $\neg\left(\mathrm{H}_{\mathrm{c}} \wedge \mathrm{H}_{1} \wedge \mathrm{H}_{2} \wedge \mathrm{H}_{3}\right)(1,2$ modus tollens $)$

(4) $\neg \mathrm{H}_{\mathrm{c}} \vee \neg \mathrm{H}_{1} \vee \neg \mathrm{H}_{2} \vee \neg \mathrm{H}_{3}$ (3, De Morgan)

Basta uma das hipóteses auxiliares ou a hipótese central ser inadequada para que o teste não funcione como esperado. Nesse sentido, enquanto um cientista pode se encontrar na situação de rejeitar $H_{c}$, outro preferirá excluir $\mathrm{H}_{1}$ (ou qualquer outra das hipóteses auxiliares), outro ainda um subgrupo da conjunção inicial. Se essa situação está de acordo com a prática científica real, então há muitas possibilidades de explicações para os resultados empíricos.

De acordo com Chakravartty a versão mais atual da subdeterminação é a de que é sempre possível construir teorias diferentes concordando com os mesmos dados empíricos:

Dada uma teoria, $\mathrm{T}_{1}$, é sempre possível gerar uma teoria empiricamente equivalente, mas diferente, $\mathrm{T}_{2}$. $\mathrm{T}_{2}$ é uma teoria que faz precisamente as mesmas reivindicações sobre os fenômenos observáveis que $\mathrm{T}_{1}$, mas difere-se em outros aspectos. $\mathrm{T}_{2}$ pode, por exemplo, excluir todas as entidades e processos inobserváveis de $T_{1}$, ou substituir alguns ou todos eles por outros, ou simplesmente alterá-los, mas de tal maneira a produzir exatamente as mesmas predições observáveis. Dado que tal sorte de manobra é sempre possível, como alguém decide entre teorias rivais assim construídas? (CHAKRAVARTTY, 2007, p. 7)

Enquanto possibilidade lógica, a subdeterminação é uma virtual ameaça ao realismo científico e, se houver de fato uma situação tal como descrita acima por Chakravartty, qualquer decisão entre teorias se fará com base em valores não necessariamente epistêmicos. Aqui a ideia de uma ameaça puramente virtual é reforçada porque talvez seja o caso de que não haja de fato nenhuma situação em que duas teorias sejam empiricamente equivalentes e que se diferenciem apenas nos tipos de processos e entidades inobserváveis que 
mencionam. Podemos citar aqui pelo menos dois pares de teorias concorrentes cujas consequências empíricas são bastante próximas (quando observadas algumas condições), mas dificilmente seriam consideradas empiricamente equivalentes nos dias atuais: 1) a teoria cinética dos gases, substituindo a segunda lei da termodinâmica e 2) a relatividade especial substituindo a mecânica (e a gravitação) newtoniana. Em ambos os pares, temos equivalência somente em condições muito específicas e, as consequências empíricas são ligeiramente diferentes. Aliás, essa ligeira diferença é uma das responsáveis pela mudança teórica, principalmente quando resultados mais precisos são requisitados pelos pesquisadores. Qualquer realista poderia apelar para o fato de que os resultados não são propriamente equivalentes, embora sejam bastante próximos, alegando assim que não temos aí nenhum caso de subdeterminação, apenas progresso em aproximar da realidade.

\section{Estratégia realista e novos velhos problemas}

$\mathrm{Na}$ tentativa de estabelecer um posicionamento mais sofisticado e imune à lista de Laudan ou às críticas de van Fraassen, as formas de realismo científico mais comumente defendidas atualmente são pautadas por um componente cético, no qual deve-se especificar sobre quais aspectos da ciência devemos ser realistas, suspendendo o juízo sobre as demais partes.

Uma estratégia seletiva é a oferecida pelo realismo de entidades e seus desenvolvimentos mais recentes. Originalmente proposto por Hacking (1983) e Cartwright (1983), o realismo de entidades procurou ressaltar a experimentação em detrimento da teorização, insistindo na realidade de entidades cujas propriedades fossem manipuladas a ponto controlar e/ou produzir outros fenômenos, intervindo na realidade. De acordo com Hacking, não faz sentido duvidar de uma entidade quando ela, com suas propriedades empiricamente conhecidas, é usada como ferramenta de intervenção em outras partes da realidade. Cartwright, por sua vez, visando responder ao empirismo construtivo, procurou estabelecer diferenças entre a inferência à melhor explicação e a inferência à causa mais provável. Nas inferências causais, segundo a autora, há um comprometimento existencial (aquilo que aponto como causa de um fenômeno é real) e, ao contrário de explicações teóricas, não admite redundância. A não redundância é exclusiva da inferência causal porque uma explicação causal de um fenômeno determinado não pode coexistir com outra explicação causal para o mesmo fenômeno. Não há tal exigência entre duas explicações teóricas: frequentemente se supõe que uma teoria menos geral pode ser reduzida a uma teoria num nível mais alto. Assim, uma explicação sobre um fenômeno de queda livre, por exemplo, pode ser dada quer pela equação de Galileu (na qual a aceleração é constante) quer pela equação da gravitação de Newton (onde a aceleração varia com a altura) quer pela equação do campo de Einstein (com muito mais variáveis). Cada explicação no nível mais alto é compatível com a do nível inferior pelo menos para o domínio ao qual a teoria reduzida remete.

Cartwright e Hacking admitem a possibilidade de sermos realistas sobre entidades e antirrealistas sobre as teorias nas quais tais entidades aparecem. Tal estratégia permite, por exemplo, explicar tanto a persistência de entidades como o elétron em arranjos teóricos diferentes (as propriedades experimentais do elétron persistem) quanto o ocaso de várias entidades com as teorias que as propuseram (nunca foram ferramentas experimentais). Assim, levantar dúvida sobre um ou vários ou mesmo todos os modelos atômicos não impede de assumir a realidade dos componentes subatômicos que podemos utilizar para provocar este ou aquele efeito desejado, cuja causa parece remontar às propriedades experimentalmente bem conhecidas. O posicionamento de Hacking e Cartwright tem alguns problemas, menciono aqui dois: (i) Como saber que elétrons existem sem supor a verdade aproximada de parte das teorias nas quais tal enti- 
dade é suposta? ii) Em última instância, o argumento experimental não é similar ao argumento do sucesso, dependendo, também ele de uma inferência abdutiva? Uma resposta a tais críticas pode ser dada, penso eu, nos desenvolvimentos mais recentes das intuições do realismo experimental (como os de Suárez [2008], Charkavartty [2007]e[2017] e Egg [2012]). ${ }^{4}$ Por uma questão de objetivos deste texto, deixarei tais réplicas de fora.

Já a estratégia estruturalista se fixa num aspecto pouco ressaltado pelo realismo explanacionista e numa direção diferente da do realismo de entidades. Assumindo a metaindução pessimista e a consequente possibilidade constante de substitituição de uma teoria por outra, ainda assim é possível admitir que algo é retido em cada caso de mudança teórica: a estrutura do mundo natural, mapeada corretamente mesmo pelas teorias obsoletas. As alterações nas teorias ocorrem naqueles elementos descritivos, ou seja, não estruturais. Em outras palavras, o realismo estrutural enfatiza mais as relações mesmas do que os relata (as coisas que se relacionam). Podemos dividir tal realismo em realismo estrutural epistêmico e realismo estrutural ôntico. O primeiro (no qual essa exposição se concentrará) estabelece que só podemos conhecer os aspectos estruturais da realidade, de modo que a natureza das coisas cujas relações definem estruturas está além do alcance de nossa possibilidade de conhecimento. Já o realismo estrutural ôntico é mais radical, ao afirmar que não há entidades, apenas estrutura. O ressurgimento do realismo estrutural é devido a John Worrall (1989), para quem a conservação das equações de Fresnel na teoria eletromagnética de Maxwell mostra que a estrutura da realidade é mantida mesmo quando cada teoria diverge sobre a natureza da luz. Como o apelo a equações matemáticas não melhora o entendimento do que significa 'estrutura', foi preciso ao realista estrutural epistêmico recorrer à epistemologia estruturalista de Russell (1927) para realizar essa clarificação. Para Russell só os dados dos sentidos (sense data) são conhecidos por contato (acquaintance), enquanto o conhecimento do mundo exterior se dá por uma descrição que se limita espelhar a estrutura do mundo exterior. De acordo com o filósofo britânico, de tudo aquilo que comporta a realidade extramental só a estrutura pode ser conhecida. O realismo estrutural, a bem da verdade, não adota essa perspectiva russelliana para objetos exteriores observáveis, mas consideram-na um bom modelo para restringir o conhecimento de uma realidade inobservável somente à sua estrutura.

As versões sofisticadas do realismo explanacionista são exibidas, por exemplo, por Lipton (1993 e 1994), Psillos (1999) e Sankey (2001), que procuraram especificar quais seriam os elementos de uma teoria responsáveis pelo sucesso da mesma (a manobra seletiva é conhecida pela expressão 'divide et impera') e quais tipos de sucesso seriam indícios da verdade aproximada de uma teoria. A solução do explanacionismo para o desafio pessimista seria, portanto, afirmar a verdade aproximada somente das teorias capazes de fazer previsões de fenômenos antes desconhecidos e/ou capazes de explicar fenômenos que, apesar de conhecidos, não foram utilizados na sua formulação:

Novo sucesso pode ser dividido entre dois tipos: novidade temporal, no qual os fenômenos previstos são desconhecidos dos cientistas no tempo em que a previsão é derivada e novidade de uso, uma forma menos exigente, na qual os fenômenos podem ser conhecidos mas não foram usados na formulação da teoria. (LYONS, 2002, p.69)

\footnotetext{
${ }^{4}$ Minha proposta de reabilitação do realismo experimental concentra-se em dois pontos: a consideração do realismo experimental como critério epistêmico (um critério para justificar entidades e não para descobri-las) e um acento nas propriedades antes que nas entidades mesmas. Os pormenores da minha abordagem poderão ser consultados em Oliveira (2019) (em edição).
} 
Ocorre que mesmo nessa formulação sofisticada, a hipótese realista enfrentaria os novos sucessos das teorias do calórico, do éter e do flogisto (já presentes na lista de Laudan), bem como de várias outras teorias consideradas falsas à luz de teorias atuais. Lyons cita um grande número de teorias em desuso que forneceram novas predições à sua época: a teoria do vórtice de Rankine, a teoria da molécula de benzeno de Kekulé, a teoria atômica de Dalton e a de Bohr, etc. Essas e outras formulações teóricas apresentaram à sua época novas previsões e os constituintes teóricos supostamente responsáveis pelo sucesso (ou indispensáveis para a teorização) vieram a se mostrar mais tarde inúteis nas elaborações das teorias seguintes. Assim, tais novos sucessos serviriam como instâncias contrárias ao argumento sem milagre e, mesmo se seletivamente apontamos apenas para teorias de sucesso surpreendente como aproximadamente verdadeiras, o realismo explanacionista continua ameaçado pela história da ciência. Isso fica evidenciado também num texto de Peter Vickers, cujo nome é bastante sugestivo: A confrontationofconvergentrealism (2013). No artigo, Vickers retoma a lista de Lyons (2002) e apresenta nada menos do que 20 teorias capazes de contestar a relação entre novas predições e verdade aproximada. Não temos a intenção de reproduzir aqui toda a lista de Lyons ou a de Vickers, mas a lição dada é a mesma: qualquer que seja a versão de realismo a ser construída, sua defesa precisa levar em conta os contraexemplos que a história da ciência oferece de modo a acomodar tais casos e a refinar os critérios do que é que deve ser retido e o que é que pode vir a ser substituído em uma futura mudança teórica. De acordo com Vickers, os 20 contraexemplos sugeridos podem ser apenas a ponta do iceberg dessa necessidade de refinamento e, apesar disso, ele parece otimista com a possibilidade de o realista oferecer ao menos um meio de descobrir quais são as peças soltas da engrenagem teórica:

O realismo divide et impera precisa ser desafiado por e desenvolvido à luz de todo o registro histórico. E esse registro é muito mais rico do que as discussões de longa duração de Fresnel, do calórico e do flogisto deixam aparecer. Os 20 exemplos apresentados (...) podem muito bem ser a ponta do iceberg. E cada exemplo tem o potencial de trazer algo novo para o debate. [...] Em tudo isso, encontramo-nos mesmo 30+ anos depois de Laudan (1981) - inseguros da extensão do sucesso que a estratégia divide et impera pode ter. Mesmo se os 'postulados ativos' ('workingposits') da ciência contemporânea não podem ser prospectivamente identificados, permanece possível que devamos desenvolver uma receita para identificar alguns postulados ociosos (idleposits). Isso seria um feito significante, mesmo se não for bem o que o realista originalmente tinha em mente. (VICKERS, 2013, p. 209)

Não bastasse a persistência de listas à laLaudan, há também um novo desafio ao realismo explanacionista que mistura elementos da metaindução pessimista com os da subdeterminação. Kyle Stanford (2006) chamou tal desafio de "problema das alternativas não concebidas". O argumento consiste no reconhecimento de casos de subdeterminação recorrentes e transientes ao longo da história da ciência, de modo que por uma nova indução pessimista fica impossível ter certeza que uma teoria atual é aproximadamente verdadeira, já que pode aparecer uma alternativa incompatível com a teoria que visa substituir, mas confirmada pelos mesmos dados. Enquanto o primeiro passo do argumento pessimista de Stanford recorre à subdeterminação recorrente e transiente, o segundo passo ocorre através da constatação de que a mesma falha ocorrida no passado ameaça a concepção das teorias atuais, uma vez que não há diferenças significativas no processo de teorização atual em relação ao passado. Além do mais, hoje, como no passado, esse processo depende de inferência eliminativa. Este segundo passo é similar à indução pessimista original: depois de reconhecer casos de subdeterminação recorrente e transiente ao longo da história da 
ciência, é possível supor que o mesmo destino espera as teorias maduras da atualidade. ${ }^{5}$ De acordo com Stanford, o problema das alternativas não concebidas não se confunde com a metaindução pessimista, já que o foco é na subdeterminação e não no sucesso das teorias. Tentativas tais como o realismo das novas predições, ou mesmo a distinção entre postulados ativos e inativos (como no divide et impera), procuraram responder adequadamente à primeira indução, muito embora, na opinião de Stanford, tais respostas consistem em "vitórias pírricas".

A discussão sobre a estratégia seletiva das formas mais debatidas de realismo científico na atualidade precisa justamente avançar numa resposta sobre se os elementos sobre os quais se admite o realismo não seriam ecos de uma vitória pírrica.

\section{Referências}

Carman, C. (2005). "Realismo científico" se dice de muchasmaneras, al menos de 1111: una elucidacióndel término "realismo científico". ScientiaeStudia, 3(1), 43-64.

Cartwright, N. (1983). HowtheLawsofPhysics Lie. Oxford: Clarendon.

Chakravartty, A. (2007). A Metaphysics for Scientific Realism:Knowing the unobservable. Cambridge University Press.

Hacking, I. (1983). RepresentingandIntervening:IntroductoryTopics in thePhilosophyof Natural Science. Cambridge University Press.

Laudan, L. (1981). A confutation of convergente realism. Philosophyof Science 48 (1):19-49.

Lyons, T. D. ScientificRealismandthePessimistic Meta-modus Tollens. In Clarke, S.; Lyons, T. D. (eds.). Recent Themes in thePhilosophy of Science:Scientific Realism and Common sense. Dordrecht: Kluwer, 2002, pp 63-90.

Lyons, T. D. (2011). The Problem of Deep Competitors and the Pursuit of Epistemically Utopian Truths. Journal for General Philosophy of Science / Zeitschrift für Allgemeine Wissenschaftstheorie 42 (2):317-338.

Psillos, S. (1999). ScientificRealism: How Science Tracks Truth. Routledge.

Putnam, H. (1975). Mathematics, Matter and Method. Cambridge University Press.

Putnam, H. (1978). Meaningandthe Moral Sciences. Routledge\& K. Paul.

Sankey, H. (2001). Scientific Realism. Theoria 48 (98):35-54.

Stanford, P. K. (2006). Exceeding Our Grasp: Science, History, and the Problem of Unconceived Alternatives. Oxford University Press.

Oliveira, T. (2014). Algumas razões para levar a sério a metaindução pessimista. Principia: an international jornal of epistemology, 18(2), 269-290. doi: https://doi.org/10.5007/18081711.2014v18n2p269

Oliveira, T. (2019). Uma proposta em dois passos para reabilitar o realismo experimental. Kriterion n.144, pp. 727-748. (Em edição)

Van Fraassen, B. C. (1980). The Scientific Image. Oxford University Press.

Van Fraassen, B. C. (2007). A imagem científica. Trad. Luiz Henrique de Araújo Dutra. Editora

5 Também este desafio possui uma versão dedutiva, proposta por Lyons (2011). 
Unesp; Discurso Editorial.

Vickers, P. (2013). A Confrontation of Convergent Realism. Philosophy of Science 80 (2):189-211.

Worrall, J. (1989). Structural realism: The best of both worlds? Dialectica 43 (1-2):99-124.

Artigo recebido em: 04 de dezembro de 2019

Artigo aceito em: 26 de dezembro de 2019 